\title{
The Relationship Between the Serving Leadership and Ability of Managers With Organizational Trust of Sport Clubs Staffs in Erzurum
}

\author{
Gul Eda Burmaoglu \\ Correspondence: Gul Eda Burmaoglu, Faculty of Sport Sciences, Ataturk University, Erzurum, Turkey.
}

Received: June 52, 2018

doi:10.11114/jets.v6i4a.3427
Accepted: July 8, $2018 \quad$ Online Published: July 9, 2018

URL: https://doi.org/10.11114/jets.v6i4a.3427

\begin{abstract}
The main purpose of the present study was to investigate the relationship between the serving leadership and the managers' ability with organizational trust of sport clubs staffs in Erzurum. The research methodology was established based on correlation-descriptive type of study; it also was an applied type of study regarding to its purpose. The information had been gathered as field-based using the related questionnaire from all staffs of Erzurum Clubs. The research data was also gathered as ranking, qualitative and frequency-based in this regard. The statistical population of the related study was included all staffs of Erzurum Clubs. The number of the related staffs was reached to 230 people that the number of the subjects was also taken up from every club. The number of the total staffs for every sport club in Erzurum based on the information and statistics center was 230 people in 2016. The statistical sample using Morgan Table was also reached to 140 people in this study. Three questionnaires of the serving leadership, managers' ability and organizational trust were also applied in order to gather the related data testifying the related hypotheses in this research. The correlation coefficient and t-test and regression analysis also were applied in order to analyze the obtained data in this study. The results showed that there was observed a significant relationship between the scales of the serving leadership (humiliation, trust, serving and kindness) and the ability of managers with the organizational trust in Tabriz Sport Club.
\end{abstract}

Keywords: serving leadership, managers' ability, organizational trust, staffs, club

\section{Introduction}

The process of the trust has got important concept for the related study; it also is a key meaning for developing the interpersonal relations. By the development of the globalization, the importance of the trust has been considerably increasing in the social, economic, political and organizational relations so that most experts of the different sciences have also pointed to the importance of the trust role in all organizations. Most researchers have defined the trust as a mood including the positive expectations regarding to others motivations in risky situations (Asma, 2009). Also, Yildiz (2011) believed that the trust is a collective attitude towards the publication and distribution of the innovation, creation and risk ability. He also stated that the trust can provide the communications and dialectics preparing individuals to access for interacting the thinking investment. Hardin also believes that the trust has got the vastest benefit. A trusts B for the reason he assumes that the benefits of B are the main path for reaching to his own benefits. Hence, the trust is a relative case (Balikci, 2011). Also, according to Martins' viewpoint the organizational trust can be categorized into two groups of manager personal aspects and managerial aspects. The personal aspects include recognizing the tasks, family relative, humanistic solidarity, vastness of experiences and exterior issues; the managerial tasks include the team-based management, division of information, occupational support and confidentiality (Greenleaf, 2007). Along with the carried out studies regarding to the organizational trust, it is specified that researchers have pointed to many various factors regarding to the influence of the trust on organizational issues such as the variables of the managers' ability and serving leadership (Dinc, 2009) that these have been investigated in governmental and private institutions and organizations potentially. The theory of the serving leadership is firstly led by Greenleaf in 1977 in an article titling "the serving in the role of leadership" (Washington and Field, 2006). This theory is founded based on the service theory. According to Greenleaf, organizations cannot serve what they have been considered (Dinc, 2009). Hence, the motivation and purpose theory, praise of leaders towards serving issues and its influence on the society should be paid attention importantly and the creation of a serving society is the ultimate purpose of the related theory. According to him, accessing to this kind of society requires having this kind of serving manager in all organizations that these should be also efficiently participated in the society (Humphreys, 2005). The trust atmosphere appears when the managers will be committed to achieve their tasks having predictable behaviors; Russell believes that the trust is the main origin of the 
serving leadership. Greenleaf believes that the serving leadership is the main introduction and fruit of the organizational trust. Paying attention towards others in serving leadership and considering the benefits of the successors over the personal leadership issues play key role in the construction of the organizational trust (Asma, 2009). The managers' ability is reached to its climax in 1990s being continued till now and it also has got some various influences on many organizations (Balikci, 2011). The word "ability" is subjected to have ability, option, skill, knowledge, merit and certification. According to Sherman (2001) the ability, knowledge and skills are subjected to those attitudes that a person has to get in personally. Based on this, in this research along with correlation approach, the investigation of the relationship between serving and ability of managers should be evaluated for Tabriz clubs staffs organizational trust affairs because this will also specify the relationship between them and the staffs. Although the results of some former studies represent the existence of the relationship between the serving leadership and managers' ability with organizational trust but it seems that there is observed a significant difference in the results of these studies that these should be also represented potentially. In other words, in the investigation of the relationship between the serving leadership and the managers' ability with organizational trust, the results of the different studies are controversial or they have not been represented sufficiently. Also, in this study the subjects are the staffs of Erzurum Clubs having the most challenging tasks due to their environmental issues. Dinler (2001) showed that there is a positive significant relationship between the transformational and interactive leadership style with the staffs' organizational trust but there is no observed a significant relationship between the task-based leadership styles of managers with the organizational trust. Balikci (2011) concluded that when the behavior of the managers with serving leadership indexes is getting increased, the degree of the staffs' trust will be also increased efficiently. Kuzucuk (2014) concluded that the ability and merit of leaders and their trust can increase the importance of achieving all tasks recovering the trust level of staffs. Ashja et al (2013) reported in their studies that the existence of the serving leadership can increase the organizational trust of staffs recovering and healing the functions of these staffs. Eberline (2014) concluded that there is a strong positive relationship between all dimensions of the serving leadership and the organizational commitment. Anderson (2015) reported that the serving leadership can make a kind of interaction and balance between all organizational purpose and the staffs' requirements blossoming the merit and ability and commitment of all staffs in this regard. Also, the serving leadership has a relationship with the staffs' occupational satisfaction and the civil and organizational behaviors.

\section{Materials and Methods}

The research methodology was established based on correlation-descriptive type of study; it also was an applied type of study regarding to its purpose. The information had been gathered as field-based using the related questionnaire from all staffs of Erzurum Clubs. The research data was also gathered as ranking, qualitative and frequency-based in this regard. The statistical population of the related study was included all staffs of Erzurum Clubs. The number of the related staffs was reached to 230 people that the number of the subjects was also taken up from every club. The number of the total staffs for every sport club in Erzurum based on the information and statistics center was 230 people in 2016. The statistical sample using Morgan Table was also reached to 140 people in this study.

\subsection{Data Gathering Instrument}

Three standard questionnaires are also applied in this study in order to gather the related data;

Serving leadership questionnaire: this questionnaire is used to evaluate the serving leadership from the staffs of Erzurum viewpoints; this is the same Peterson serving leadership questionnaire having an authentic reliability and validity and this has also used the conformational and discovery-based analysis; in the study of Esentas et al (2013) the validity of the same questionnaire is confirmed by the use of Cronbach alpha method and halving method (0.90). Also, this questionnaire has got 28 questions and four subscales of humiliation, trust-ability, serving and kindness and it also includes a one domain of LIKERT with 5 options (never, rarely, sometimes, often and always).

Managers' ability: this has also used to measure the ability of managers in different sport fields; this has been also established based on Dinc (2009) questionnaire having 28 options; this has been also designed based on Bourglet suggestive model; the reliability and validity has been reported (0.89). Also, this questionnaire has a one domain of LIKERT with 5 options (strongly agree, agree nothing, disagree, strongly disagree).

Organizational trust: this evaluates the organizational trust using Dinc (2009) questionnaire with 11 options along with authentic reliability and validity (0.90). Also, the used scale of the questionnaire is subjected to the LIKERT 5 options beginning from very high ending to very little.

\subsection{Data Gathering Method}

The applied collections of gathering data regarding to the present study are as following:

Field-based method: this can be completed by the filled questionnaires that these will then be sent to be analyzed. All books and scientific magazines in different libraries; Using the different articles from different international resources. 


\subsection{Statistical Methods}

Pearson correlation coefficient statistical test and regression analysis are also applied to testify the hypotheses of the study. Also, the statistical methods have been carried out by SPSS20 in significance level lower than 0.05 .

\section{Results}

Table 1. Results of Pearson correlation coefficient test between humiliation, trust-ability, serving, kindness, serving leadership, ability of managers with organizational trust

\begin{tabular}{lccc}
\hline Dependent / independent & Organizational trust & & \\
\hline Humiliation & Correlation coefficient (r) & Sig & Number (N) \\
Humiliation & 0.42 & $0.04^{*}$ & 128 \\
Trust-ability & 0.58 & $0.01^{*}$ & 128 \\
Giving services & 0.63 & $0.02^{*}$ & 128 \\
Kindness & 0.48 & $0.02^{*}$ & 128 \\
Serving leadership & 0.42 & $0.02^{*}$ & 128 \\
Managers' ability & 0.67 & $0.01^{* *}$ & 128 \\
\hline
\end{tabular}

As it shown in table 1, it can be stated that there is a direct significant relationship between the humiliation, trust-ability, serving, kindness, serving leadership, ability of managers with organizational trust from the subscale of serving leadership with organizational trust in Tabriz Sport Clubs and its staffs; in other words, by increasing the humiliation, trust ability, serving, kindness, serving leadership, ability of managers with organizational trust from the subscale of serving leadership, the organizational trust will be also increased in this regard.

Table 2. Regression analysis to predict the staffs' organizational trust based on serving leadership and managers' ability model

\begin{tabular}{llllll}
\hline Table of common factors (coefficients) of organizational trust & & \\
\cline { 1 - 4 } Predicting variable & \multicolumn{2}{l}{ Non-std coefficients } & Std coefficients & T statistics & Sig \\
\cline { 2 - 4 } & $\mathrm{B}$ & Std error & Beta & & \\
\hline Fixed number & 1.940 & 0.217 & - & 3.180 & 0.000 \\
\hline Serving leadership & 0.274 & 0.086 & 0.272 & 3.180 & 0.001 \\
\hline Managers' ability & 0.408 & 0.087 & 0.381 & 4.671 & 0.000 \\
\hline
\end{tabular}

The information of table 2 represent that the regression analysis along with its variables of serving leadership and ability of managers, the power of predicting the staffs' organizational trust can be taken place significantly.

\section{Discussion and Conclusion}

The results of hypothesis 1 showed that there is a significant relationship between the humiliations of the serving leadership subscale with the organizational trust among the related staffs in Tabriz sport clubs. This result is adaptive with the results of former studies such as Ashja et al (2013), Washington (2007), Dry (2004), Greenleaf (2000), Kuzucuk (2014), Balikci (2011), Dinler (2001), Anderson (2015), Bennis et al (2005), Carnevale et al (2005). These studies represent the fact that the viewpoints of the staffs and employers of organizations regarding to the establishment of the organizational trust atmosphere are subjected to the fact that the organizational leaders with their own correct behaviors can construct an authentic atmosphere in this pavement. According to Saroun (2003), the humiliation is not merely subjected to a person's attention but also it has to pay attention to others potentially because this will be able to blossom others talents and aptitudes in this regard. Swindle believes that the humiliation is not only subjected to a person's satisfaction but also it has to pay others rights respectfully; the serving leaders have to get these features trying to meet their successors' requirements efficiently. Leaders having these kinds of features are more inspirational persons that they can assist to the society and their successors because this will also progress the organizational tasks. This kind of leadership feature cannot define the weakened staffs and for the reason, all staffs have to raise their own ability and values in order to reach to the highest level of their leadership. The organizational members have to make a kind of equilibrium between their tasks because this will also make them to participate in all organizational affairs equally. This concept of the leadership has a close relation with the organizational trust. This feature of the humiliation is a kind of power for attracting the trust of others. Indeed, the humiliation of managers is similar to obtain the successors' satisfaction. The humiliated leaders have got personal ability and merit along with their own morality and behavior preparing others to follow and obey them efficiently in this pavement. Therefore, the process of the trust is one of the most fundamental investments that this can make the reunification of all organizations together and then this will optimize the democratic values of the same organizations. On the other hand, the organizational leaders can make an interactive relationship with others in order to construct the trust atmosphere along with some simple ways such as simple moral issues; the results of the second hypothesis showed that there is established a significant relationship between the trust ability from the subscale of the serving leadership style with the organizational trust in Tabriz sport clubs. The results of the study are adaptive with the results of Charlton (2007), Facilitator et al (2003), Ashja et al 
(2013), Washington (2007), Dry (2004), Greenleaf (2000), Kuzucuk (2014), Balikci (2011), Dinler (2001), Gareth et al (2003), Kipnis (2000). These mentioned studies have significant relationship with the organizational trust. The representation of the result is that the trust is subjected to a sustainable confidence based on honest, ability and or personality of a person; in other words, the trust is subjected to praise and interest of all managers to achieve some sensitive approaches in an organization. The construction of security and trust is an imperative case in this pavement; the trust is the main root of the leadership; it also is an important influential factor for penetrating into the leadersuccessor relations effectively. In absence of the trust, the fear will be shadowed over the organization reducing the efficacy in this regard. Russell considers the honest values and telling truth as the main formation framework for the organizational trust and believes that this trust is the main origin and nature of the serving leadership style. In addition, Melrouz believes that leaders acting what they believe in can construct the same trust. Also, interest and tendency of the leader towards the interior affairs can increase the trust ability and all successors will also tend to follow their leaders potentially. The process of the trust is an element for the success of an organization. On the other hand, the highest levels of the trust in organizational leaders can increase the staffs' temperament reducing the absence and increase the organizational innovation; this will also increase the organizational trust between all members. Trust-making element is the first step from the leader towards attracting the organizational trust because this will ultimately result in constructing the interpersonal relations based on honesty, cohesion and vastness of relations along with bilateral and mutual interactions. The leadership based on trust and the application of its approaches can make and bring some good consequences personally and organizationally. The leadership based on the trust is a technique that the whole leaders tend to apply this kind of approach efficiently. The results of the third hypothesis showed that there is no observed a significant relationship between the servings from the serving leadership scale with the organizational trust in Tabriz sport clubs. The results of the study are adaptive with the results of Eberline et al (2014), Ashja et al (2013), Dry (2004), Greenleaf (2000), Kuzucuk (2014). These studies mention the fact that the staffs and employers of these organizations believe that the organizational trust appears when the leaders got have serving feeling towards the organizational affairs. The main representation of the result is that the serving is the main heart of the serving leadership style. The serving leaders can also show their values and attitudes through their own behaviors. A good leader is someone that he or she serves others efficiently. These leaders have to be praised for giving the services. The serving is the main core of the serving leadership style being considered as a necessity for the moral affairs. Finally, when we take up between the personal benefits and serving others, unfortunately the personal benefit is felt more and more. The leader taking up the serving issues can provide the success of others benefits in this pavement. They serve others through giving the information, materialistic resources, time, and attention to others that these can cause to conceptualize the tasks better. The serving leaders prepare their own successors and followers for accepting the serving issues. The staffs serving others feel responsibility more. The serving process has been little paid attention in leadership discussions. For the reason, this suspicious thinking is always taking place that everyone acts based on his or her own personal benefits and others has been neglected in this pavement. The main section of the serving process is subjected to give services and this includes the ability-making that it also shows that the leaders should give their own services trying to persuade all successors in this regard. The responsibility and giving service have been potentially represented as giving services towards others. Giving services towards others is the main attention towards the organizational requirements that this sense is the same sense coming from the trust of the leadership forming the organizational trust. Block (2002) considers the movement towards the giving-service as a new paradigm regarding to the construction of the trust atmosphere into all organizations. The serving leader is someone that it has to provide and meet all needs regarding to others needs because this will attract the organizational trust efficiently. A serving leader publishing and distributing the ideas and comments can grow the organization making or changing some essential changes over the same organization efficiently. On the other hand, all staffs also feel that their managers are the real servants of people having enough trust to be a manager. The results showed that there is a significant relationship between the kindnesses of the subscale with the organizational trust in Tabriz sport clubs. Hence, the results of the study are adaptive with the results of Ashja et al (2013), Washington (2007), Dry (2004), Greenleaf (2000), Kuzucuk (2014), Balikci (2011), Dinler (2001), Peterson (2003). These studies are necessary for establishing the relationship between the organizational trusts regarding to the leaders' kindness behavior. It can be represented that the leadership and morality are the mutual belief into all organizations. Today, the consideration of the moral behavior particularly the kindness with staffs is added to the serving leadership responsibility. The kindness behavior can help organizations to make a connection with the organizational trust in critical conditions raising the performance and organizational progression. Since the leadership is an organizational technique and the conduction of the materialistic-based and humanistic facilitations, it will require the most sophisticated approaches in order to be applicable in this regard. The leader moral role is an imperative case particularly for attracting all staffs for making the organizational trust because this will also result in keeping and optimizing all motivational issues of the organizational tasks coherently. The organization's leader relying on this kind of power implies the organizational trust in the framework of the moral issues and this will lead to the cooperation 
between individuals, groups and organizations facilitating the effective communications in this regard. the results showed that there is a significant relationship between the serving leadership with the organizational trust in Tabriz sport clubs staffs. This result is adaptive with the results of Ashja et al (2013), Washington (2007), Kuzucuk (2014), Bryant et al (2003), Humphreys et al (2005) and Li et al (2005). These represent the fact that the organizations' staffs and serving leaders are the most effective factors for recovering and healing the effectiveness of all organizations and these are also considered as the organizational trust. The organizational trust is one of the most effective factors for recovering the whole organizations' efficacy. Due to the results of the present study, the serving leadership style has a strong positive relationship with the organizational trust. The serving leaders are not merely exclusive due to the style of the leadership but also they are very distinct leaders for their surrounding affairs. For the reason, the positive leaders and managers should be potentially grown and nurtured being able to be applied in organizations. The honesty and telling truth is one of the most traits and features of the managers. These managers and leaders can praise their own staffs by showing the same honesty in order to absorb and attract the organizational atmosphere in this regard. On the other hand, the cooperation temperament can be efficiently raised and developed into all organizations. Managers and leaders should try to be exposed to their staffs' availability because this will make all staffs not to feel that they are separated from the organizational tasks. These managers should also listen to daily negotiations of their staffs paying attention to all comments and ideas potentially. The transparency of all affairs into an organization, behavior of managers and representation of all purposes and organizational plans can also optimize the trust atmosphere into organizations. Relying on the affairs through managers and leaders can also make the necessary reliability of the organizational issues and this will also attract the trust of the staffs. Appreciating all struggles and others strives is one of the most fundamental features of the serving leadership. Thus, managers and leaders should grow and nurture the best communicative approaches among their staffs in order to recover the trust into related atmosphere. Allocating the given tasks through the leader into staffs can be considered as a powerful stimulant for all staffs; when manager trusts over his staff, there will be established a strong interaction resulting in making the best decisions and approaches efficiently. The serving leaders divide all responsibilities with their staffs because this will lead to find some better opportunities for the successors and followers. Indeed, a part of the serving leadership is similar to the role of a teacher supporting and appreciating all tasks and by this way the trust plays a key role in all organizational affairs. Appreciation and support of all managers and higher leaders can give a kind of personality to all staffs constructing the developed necessary motivation for these staffs. The construction of an effective relationship with successors and their participation into the organizational information are the main fundamental traits and features of the serving leadership. If the managers do not share their staffs in relation to the information affairs, it cannot be expected that the responsibilities will be accepted; sharing in information can make a better atmosphere of the trust bringing all intimacy and responsibility between individuals of an organization. Indeed, sharing the information can cause staffs to get familiar with many various activities of the same organization. This makes all staffs to get ready for accepting many different tasks and responsibilities. The results showed that there is a significant relationship between the ability of managers and the organizational trust in Tabriz sport clubs. This result is adaptive with the results of Abraham et al (2001), Bourgault et al (2006) representing that staffs feels the organizational trust into an organization when the leaders will achieve their tasks and responsibility with best ability.

\section{References}

Abraham, S. E., Lanny, A. K., Kenneth, S., \& Manuel, A. M. (2001). Managerial competencies and the managerial performance appraisal process. Journal of Management Development, 20(10), 842-852. https://doi.org/10.1108/02621710110410842

Anderson, J. (2015). The writings of Robert K. Greenleaf: An interpretive analysis and the future of servant leadership. Servant Leadership Research Roundtable. Regent University.

Ashja, A. (2013). To Investigate The Relationship Personnel's Perceived Organization Justice and Trust (Organizational Trust and Supervisor Trust). Knowledge and research in applied Psychology.

Asma, H. (2009). A review on the relationship between the organizational identity and organizational trust, two-monthly magazine of human resources.

Balikci, S. H. (2011). The investigation of the serving leadership and staffs' organizational trust, Magazine of Governmental Management, 1(3), 42-48.

Bourgault, J., Charih, M., Maltais, D., \& Rouillard, L. (2006). Hypotheses Concerning the Prevalence of Competencies among Government Executives, According to three organizational variables. Public Personnel Management, 35(2), 89-114. https://doi.org/10.1177/009102600603500201

Dinc, H. (2009). The Optimization Of the organizational trust in governmental section: the investigation of the role of managers' managerial ability, Managerial Studies, 2(4), 412-420. 
Eberline, R., \& Tatum, C. H. (2014). Organizational justice and decision making (When good interactions are not enough), Management Decision, 1040-1048.

Esentas, K. (2013). The relationship between the serving leadership style and the personal creation of staffs, The Contemporary Studies in Sport Management, 3(6), 215-220.

Humphreys, J. H. (2005). Contxtual Implications for Transformational and Servant Leadership: A Historical Investigation. Management Decision, 43(10), 1410- 1431. https://doi.org/10.1108/00251740510634949

Kuzucuk, S. (2014). The effect of the serving leadership style on the staffs' organizational trust, a thesis for MA, university of Adiyaman.

Sherman, R. (2001). Management competencies and sample indicators for the improvement of adult education program, A Publication of Building Professional Development Partnerships for Adult Educators Project. http://www.prenet2000.com

Tschannen, M. M. (2010). Fostering Organizational Citizenship in Schools: Transformational Leadership and Trust. In: Studies in Lead in Schools, Hoy W.K. An C.G. Miskel (Eds.). Information age publishing, Greenwich: CT, 157179.

Washigton, R., \& Field, H. S. (2006). Individual difference in servant leadership: The roles of values and personality, Leadership and Organization Development Journal, 27(8), 700-701. https://doi.org/10.1108/01437730610709309

Yildiz, M. (2011). The relationship between the serving leadership with the trust over supervisor, trust over organization and social-civil behavior in nurses of governmental educational hospitals of Shiraz City, Seasonal Magazine of Hospital, 10(3), 25-32.

Yilmaz, K. (2008). The relationship between organizational Trust and organizational commitment in Turkish Primary Schools. Journal of Applied Sciences, 8(12), 22-28. https://doi.org/10.3923/jas.2008.2293.2299

\section{Copyrights}

Copyright for this article is retained by the author(s), with first publication rights granted to the journal.

This is an open-access article distributed under the terms and conditions of the Creative Commons Attribution license which permits unrestricted use, distribution, and reproduction in any medium, provided the original work is properly cited. 